\title{
Semiosis without Consciousness? An ontogenetic perspective
}

The aim of this article is to elaborate my claim that the existence of semiosic processes does not always imply the presence of consciousness. This may seem a provocative statement since there are certainly good reasons to assume that consciousness and semiosis are merely different aspects of one and the same phenomenon. Indeed, I am convinced that consciousness always includes what we might define as a semiotic function, and that we therefore cannot have consciousness without semiosis. However, such an implication does not necessarily imply the opposite; and we might well envision the presence of semiosis before we have fully developed consciousness. I base my argument here on empirical data from the earliest phases of neonate ontogenesis. I argue that in order to fully understand how semiosis develops in very early interactions between adults and neonates, we need to abandon the traditional internalist cognitivist view of mind and representations, and adopt an alternative, externalist, semiotic perspective, that draws on the work of both Vygotsky and Peirce. The external mind is not entirely in the intentional subject, nor in the object, but in the intersubjective space of their interaction, the analysis of which must take into account emotion, affect, perception and bodily sensation. My starting point is a brief discussion of ways in which semiotics up to now has viewed the relationship between consciousness and semiosis.

\section{Semiosis and Consciousness: A background sketch}

The relationship between consciousness and semiosis has been a constant object of inquiry for semiotics, underlying, often implicitly, the very definition 
of what a sign is. Indeed, the basic distinction between intentional and nonintentional signs that has characterised the whole history of the discipline since its foundations, presupposes a reference to the idea of consciousness as intentional agency, intentionality becoming, thus, a crucial dimension in the definition of sign typologies.

Even more intriguing is the issue of the relevance of consciousness in relation to semiotic activity in itself. If we are prepared to agree that we clearly can have signs that are not consciously produced, can we then speak of genuine processes of semiosis outside of conscious organisms? Does semiosis blend or merge completely with consciousness, or do these two concepts actually refer to at least partially separate domains? Obviously, the answer to this question largely depends on what we mean by the two terms in question and how we decide to define both 'consciousness' and 'semiosis'.

Consciousness is a typical umbrella term that is used to cover a wide range of different concepts, from phenomenal awareness and the distinction between self and non-self, to higher levels of reflexive consciousness and the notion of first-person perspective. I shall not begin to go into these complex issues ${ }^{1}$ here, but rather concentrate on the other term in our problematic couple, i.e. 'semiosis'.

One way to do this is to look at the way in which the discipline that studies processes of semiosis, i.e. semiotics, defines its object. Clearly, depending on the way in which we decide to define this particular object, we will arrive at very different answers to our principle question regarding consciousness itself.

Semiotics, too, does not have any easy definition of itself: already in 1979, Eco began to address the issue of whether semiotics ought to be taken as a field or as a discipline. Whatever option we decide to settle for, we will have to confront the dualistic theoretical foundations of the discipline, rooted as it is on the one hand in the early structurailist approaches of Saussure and Hjelmsiev, and on the other in the philosophical pragmatism of Peirce. These two foundational stances differ deeply in respect to our problems in hand, since they construct their reciprocal objects in different ways.

Saussure, and Hjelmslev after him, never refer to the word semiosis, since their attention is not so much on the processes that produce semiotic phenom-

1 It is impossible to list all the significant works on this particular topic; it is sufficient for our purposes here to recall the seminal works of Dennett (1991), Searle (1997), and Edelman $(1989,2004)$. 
ena, but on the systemic forms that emerge from these processes over time, i.e. structure, and first and foremost, linguistic structure.

In Saussure's definition of semiotics (sémiologie in his own words) it is quite clear that the realm of semiosis coincides with human beings and their social life. After having described the linguistic system separating langue as structure from langage - the heterogeneous set of the phenomena involved in linguistic activity - he hypothesizes a new science to come:

La langue est un système de signes exprimant des idées et par là comparable à l'écriture, à l'alphabet des sourds-muets, aux rites symboliques, aux formes de politesse, aux signaux militaries, etc. Elle est sulement le plus importants de ces systèmes. On peut donc concevoir une science qui étudie la vie des signes au sein de la vie sociale : elle formerait une partie de la psychologie sociale, et par conséquent de la psychologie générale; nous la nommerons sémiologie. Elle nous apprendra en quoi consistent les signes, quelles lois les régissent (Saussure 1916: 25).

Although Saussure does not mention the word "consciousness", his notion of the sign presupposes this, since the sign is a dual entity, comprising an acoustic signifier and a mental signified. As Eco has pointed out:

[T] he signified is something which has to do with the mental activity of anybody receiving a signifier: according to Saussure signs 'express' ideas [...] and ideas must be mental events that concern a buman mind. Thus the sign is implicitly regarded as a communicative device taking place between two human beings intentionally aiming to communicate or to express something (Eco 1979: 15, my emphasis).

It is quite clear that in this approach semiosis coincides with a highly complex intentional system, and is basically restricted to human actors. The linguistic sign is the model for any other sign; before it emerges, we cannot have any form of semiosis, only an "amorphous mass" that needs to be formed. In this way, albeit implicitly, consciousness becomes an indispensable precondition for semiosis. Hjelmslev (1943) extended this framework and developed the idea of a continuum of semiotically undifferentiated matter that must remain beyond the realm of semiotic inquiry.

As Eco has pointed out, those who share Saussure's (and Hjelmslev's, I would add) notion of semiotics "distinguish sharply between intentional, 
artificial devices (which they call "signs") and other natural or unintentional manifestations which do not, strictly speaking, deserve such a name" (ibid).

A quite different picture can be seen within the Peircean paradigm, where semiotics is "the doctrine of the essential nature and fundamental varieties of possible semiosis" (C.P. 5.488) and semiosis in its turn is "an action, an influence, which is, or involves, a cooperation of three subjects, such as a sign, its object and its interpretants" (5.484).

According to Eco it is possible to interpret Peirce's definition in a nonanthropomorphic way: "It does not demand, as part of a sign's definition, the qualities of being intentionally emitted and artificially produced" (Eco 1979: 15)

If it is not necessary for semiosis to have a human emitter, it is nonetheless necessary, for Eco, to have a human receiver. Eco's notion of sign is based precisely on this feature, and recalls the definition proposed by Morris (1938): "I propose to define as a sign everything that, on the grounds of a previously established social convention, can be taken as something standing for something else. [...] Semiotics, then, is concerned with ordinary objects insofar (and only insofar) as they participate in semiosis" (Eco 1979: 16, my emphasis).

For the Eco of $A$ Theory of Semiotics, consciousness - taken as intentional forms of consciousness - appears to be crucial for establishing limits for semiotic activity, and this can be clearly seen in his discussion of the notion of unintentional signs. According to Eco, natural or unintentional signs, such as medical symptoms, only become signs when they initiate inferential activity or, in other words, at the moment in which they become interpreted as such by a human agent. Consciousness is thus required in order to have semiosis, so to speak, only at the tail end of the semiotic chain - i.e. on the part of the interpreter. It is precisely at this moment that something potentially sensible (such as a trace) actually becomes a sign, on the basis of a "conscious" process of interpretation. Signs in themselves may be unintentionally - or unconsciously - produced, but the processes through which we attribute meaning to them - making them into real signs - are not.

In the same vein, gestures and non-rerbal behaviour in interaction become significant only when interpreted by an addressee who decides to recognize these as endowed with meaning. But certainly gestures, as executed by human beings, although often non-intentional, are always part of a complex semiotic behaviour by highly complex organisms that are also conscious. As a result, gestures may be endowed with underlying significant, but nonetheless 
unconscious, intention. Intentionality does not always have to be conscious in other words, and we always have some aspects of unconscious intentionality in our interactions with others.

As soon as we move towards threshold zones where even a "low" concept of consciousness seems not to apply, this question becomes even more clear cut. Natural, or biological, processes such as the growth of plants, or the turning of sunflowers to follow the sun, to use one of Peirce's famous examples, are not in themselves semiotic processes according to Eco, who also explicitly claims that "It is incorrect to say that every act of inference is a 'semiosic' act - even though Peirce did so" (Eco 1979: 17).

In Eco's view, only the discourses that we are able to take part in regarding natural phenomena and our interpretations of the natural habits these seem to display are to be considered semiotic activities.

\section{The lower threshold}

In this same vein, Eco postulates a number of minimal conditions that are necessary in order to define a phenomenon as semiotic, establishing in so doing, a lower threshold for semiotic activity in terms of the distinction between physical stimuli and signs.

Since everything can be understood as a sign if and only if there exists a convention which allows it to stand for something else, and since some behavioural responses are not elicited by convention, stimuli cannot be regarded as signs (Eco 1979: 19).

A crucial notion here is that of convention, a central concept in Eco's theory. It is worth remembering that in 1975 , Eco considered even iconic signs to be rooted in some form of conventional ground. He does not clarify in this context whether convention implies some form of conscious activity or not, but he certainly opposes it to behavioural responses and their automatism, imputing a certain degree of freedom of choice to the notion of convention. It therefore seems plausible to assume that conventions are initiated by way of conscious decisions, although they might well subsequently be perceived as functioning in a more automatic kind of way.

This same question is addressed again by Eco a few years later, on the occasion of a meeting with a group of immunologists (Eco 1988). Immunologists often refer to the immune system as being endowed with an internal 
system of communication, where cells communicate and share information with one another. In this context a key question was: is this only a metaphor, or can we assume that some basic proto-semiotic functioning is brought into play here? In 1988, Eco further elaborates his 1979 position, but does not radically modify it. He maintains the distinction between a stimulus-response process, which is a dyadic one and implies a casual deterministic sequence, and a triadic model where it is possible to envision a third element $C$, "call it the code, or the process of interpretation implemented through the recourse to the code" (Eco 1988: 9) interspersed between the two dyadic elements $A$ and B. Semiosis always presupposes the presence of a $C$-space, since it is always a triadic process, where C-space is a time interval, a space of possibility that permits some degree of freedom.

Therefore the conditions for semiosis coincide with the existence of an interval, a temporal gap between some stimulus and its response. This implies at least the following: i) the stimulus and the response do not have to be copresent; ii) there must be a certain degree of freedom regarding any given response; iii) as a consequence of ii) there must be some possibility of choice between different possible responses; iv) responses are not totally predictable; v) context acquires central relevance, since it will contribute to determining the most appropriate, or best fit, responses. In this way C-space marks the passage from a dyadic to a triadic model, where abductive, hypothetical forms of reasoning can take place. To summarize: C-space constitutes the threshold between semiotic and non-semiotic behaviour, between the realm of inferencing and freedom of choice, and merely deterministic, or mechanical, responses to a stimulus.

Although in 1988 Eco seems to allow for the possibility of semiosis without consciousness, for example in the case of sophisticated Artificial Intelligence systems, the relation between consciousness and semiosis still appears crucial. Indeed, since Eco equates semiosis with abductive reasoning, where the latter refers to the capacity to "take difficult decisions when following ambiguous instructions" it is difficult to imagine a total lack of at least some minimal level of consciousness. The turning of sunflowers to follow the sun, to refer once more to Pierce's famous example, would be equally well ruled out as a phenomenon of semiosis both in Eco (1988) and Eco (1979).

The C-space model sketched out by Eco (1988) has some peculiar features that deserve further discussion. First of all, it is a strongly cognitively oriented space: semiosis is seen as coincident with inferencing processes and abductive 
(or hypothetical) reasoning; focus is decisively on cognition, while emotions and affect seem to play no role whatsoever in the initial appearance of semiosis, and the same goes for perception and bodily sensations.

Second, and even more important, the appearance of semiosic processes is envisioned only within each single organism: C-space is the space between stimulus and response that emerges internally, within the single individual taken as a separate whole. We could say that this is a predominantly intra-subjective perspective, rather than an inter-subjective one. I would call it an intermalist position, where the origin of semiosis coincides with the existence of an internal space that permits decision-making and some degree of freedom of choice, and with the capacity of the single organism to draw inferences about its environment and to respond in non-deterministic ways to stimuli deriving from external agents in this environment. All this seems to be quite a good approximation of what we know as conscious behaviour.

In what follows I shall examine the relationship between consciousness and semiosis from a quite specific angle, by investigating the beginning of semiotic life in the developmental, ontogenetic dimension.

\section{An ontogenetic perspective}

There is a very good reason that underlies my choice here: ontogenesis is perhaps the only situation in which we are able to witness in a direct, verifiable way, and not merely speculatively, the simultaneous growth of both semiosis and consciousness. In the development of newborn and infant children, processes of "semiotization" cannot really be separated from processes of "subjectivization" and the emergence of consciousness. In a way, one could say that to become a subject is to become a semiotic subject. Semiosis and consciousness are then, in ontogenetic development, inextricably linked to one another.

At least, this appears to be so if we look at the internal development of each single individual, assuming a perspective similar to the one implicit in Eco's argument, that which I referred to earlier as an intermalist position. Within the single individual, semiosis and consciousness tend to coincide or at least to merge into one another: the newborn starts to exhibit some kind of semiotic awareness at the same time as other elements of consciousness begin to develop in its cognitive system. There is good evidence of this if we look more closely at what is called the "pointing finger experiment". ${ }^{2}$ Until the age of

2 For a description and discussion of this specific experiment see Stern (1985). 
approximately 8-9 months, whenever the mother, or another adult caretaker, points a finger in front of a neonate, as if to indicate something else that is present, the newborn looks only at the finger, never turning her head in the direction of the pointing finger. Around the ninth month children radically change their behaviour, and start doing something quite different. First, they look in the direction of the pointing finger, and then they do something even more interesting, they turn their gaze to the mother's eyes, as if to verify that their reaction was correct, eventually readjusting their gaze direction in the event that it appears not to have been so.

We could say that this is a clear instance of the beginning of semiotic awareness: the finger stops being just an object in itself, merely a part of the mother's body to be looked at, and that it acquires a full semiotic function. Indeed it becomes a sign, more precisely an index, according to Peirce's terminology. This means that the neonate is aware that the finger is not the intended object of attention, but 'stands for something else': the object that is being pointed at by the mother. In other words, the finger becomes a device that is being used to signify something else. This is obviously the basis for what we have called semiosis. In the transformation from 'finger' to 'index' an interval has been introduced, a $\mathrm{C}$-space where some form of abductive reasoning begins to take place, as shown by the neonate turning her head to the mother, as if to check whether her inferences regarding the meaning of the indexical sign are correct.

As I said, this happens around the ninth month of life, a crucial turning point in the development of neonates' mental life, when they appear to become more conscious of their own mental states as well as those of others. We might say that the development of semiotic awareness is part of a more general process of emergence of consciousness, and that, from an internalistic perspective, both these phenomena mutually presuppose one another.

Should we then deduce that there are no semiotic processes before the emergence of consciousness? In other words, what can we say about semiosis and consciousness in the very first months of life?

The main point I would like to emphasize here is that semiosis starts much earlier than consciousness does, but that in order to see this happening, we need to shift our perspective from the mental, internal development of the child to something else, i.e. to the external world that includes both the newborn and its social and material environment. To disentangle, so to say, semiosis from consciousness, we have to ask different questions from those 
that characterise the more classical developmental perspective, which, to some extent, is the same type of perspective adopted by Eco in his discussion of Cspace.

For example: how exactly does the process of becoming a competent "semiotic subject" come about? Through which stages, under which constraints, and by way of which modalities does a newborn infant become a semiotic being?

Over the last 30 or so years a consistent body of research has been developed around the very first months of newborns' lives, using innovative research methodologies and obtaining some novel and important results not previously available to psychologists. This wide-reaching international research project is known as Infant Research (hereafter I.R.) and has, since the 70's, fostered interdisciplinary forms of cooperation between developmental psychologists, psychoanalysts, paediatricians, neurophysiologists in investigations of very early life stages of newborn infants. ${ }^{3}$ The methodological and theoretical presuppositions of I.R. are somewhat different from those of more traditional psychoanalytic approaches which are mainly based on speculative assumptions and the development of theoretical hypotheses. ${ }^{4}$ The novelty of I.R. is its empirical methodology, which is based on both experimental data 5 and direct observation on the basis of video materials.

The picture that emerges from the impressive data corpus collected within the paradigm of I.R. appears to be very different from the one depicted by classical psychoanalytical approaches, where the infant is seen as autistically closed in a form of primary narcissism (Freud 1914) or fusionally and symbiotically united with the mother (Mahler 1968, 1975).

On the contrary, newborn infants appear to be endowed with a highly specialised capacity for making distinctions and discriminating among a wide range of domains that pertain to different perceptual and sensory sources - the

3 To quote only a few seminal works in what today is an immensely developed field of research see: Stern (1985), Neisser (1993), Tronick (1982), Tronick et al. (1978), Trevarthen (1991).

4 It was first with Esther Bick (1964), that the observational paradigm was initiated - Infant Observation - which, although it cannot be called experimental, is based on direct observations of neonates.

5 Experimental data come mainly from two sources: behavioural and neurological evidence. Both measure or record relevant changes in usual behaviour (or in usual neurological activity) of infants. In both cases the key concept is habituation. Changes in normal patterns of behaviour and/or neurological activity may indicate that the infant notices something different and reacts to the change. Changes in behaviour are often measured as differences in sucking intensity, which is relatively easy to register using special teats, or in head-turning or gaze movements. 
visual, the auditory and even the affective domains. A few days, if not hours, after birth babies are already able to distinguish the smell of their mother's milk from that of another woman; they can recognize human voices from other sounds that are not voices, and, among different human female voices of the same age speaking the same language, they are able to distinguish the voice of their own mother. Very early on, the visual motor apparatus of the newborn infant is already developed, and it has already functioning systems of reflexes that control ocular movements that allow it to fixate on objects in space.

Of a particular interest are experiments showing the high capacities of imitation in newborns. As early as a few hours after birth, newborn infants are able to exactly reproduce facial gestures performed by an adult, like protruding of the lips or tongue and opening the mouth, ${ }^{6}$ certainly without having seen them before and even without having seen a human face before.

Even more interesting are data concerning the precocious intersubjective competence of neonates, and their capacity to respond to external stimuli and interact in a meaningful way with the environment, as shown in the seminal experiment by Tronick et al. (1978) known as the "still face" experiment. During the course of a normal playful interaction between infant and mother (or father), the adult is asked to stop the interaction and maintain a still face without any particular expression for a few minutes (generally two minutes), altering in this way the expected sequence of actions. At the age of three months, and even earlier, children react in a highly complex and interactive way to this experience. First they generally look disoriented and show a certain level of annoyance, then they try to involve the absent mother by touching her face, smiling, and trying to force an interactive move on her side. When they do not succeed, there is a third phase, which can involve retiring into themselves or crying. The sequence may vary, and there are individual variations among children, but all exhibit a strong interactive competence that is far from the autistic narcissism imagined by Freud. This experiment also casts doubt on the idea of a totally symbiotic fusion with the mother, since newborns appear to be quite aware of the otherness of the mother, and of changes in her behaviour, very early on indeed.

So what can we infer from all this evidence? Certainly we are witnessing highly complex forms of semiotic behaviour: babies are much more competent in interacting with their environment and with relevant human figures around 
them than it was ever supposed before. Their capacity to respond in appropriate ways to external stimuli and to engage in appropriate intersubjective exchanges is striking, and microanalysis using new systems for video-recording and detailed analysis of these have made it possible to observe this in minute detail. Stern uses the term "interactive dance" to describe complex interactive behaviour of this kind, which is characterized by the use of highly complex semiotic synchronization devices on both sides of the "dance floor".

The crucial question, however, is whether we can also deduce, on the basis of an existent semiotic competence in the behaviour of early children, the existence of high-level consciousness in their mental apparatus.

This question is quite open and has not had, until now, any definite, clear answer, since it is very difficult to infer from specific behaviours the existence of any given mental state. In a way, in the case of neonates we run the same risk that we face in zoosemiotics while analysing animal behaviour: we risk projecting our own human categories and interpretative schemas onto an otherwise quite different type of behaviour. If, with animals, the risk is anthropomorphizing them, in the case of neonates we could risk "adultomorphizing" them, but essentially the question is the same. As Nagel (1979) pointed out, the only way to gain evidence of subjectivity and consciousness of a given system is being that system yourself, and, I would add, expressing that experience in words. Since this is not possible for either animals or neonates, we are left with no more than mere speculation.

In the field of Infant Research there is not one single definitive answer to this question, although there is common agreement on the early competencies of newborns. Trevarthen (1993) claims for example that activities of newborns are not reflex actions, and he assumes a level of consciousness right from the moment of birth, while Stern seems to me more cautious on this specific point: the sense of Self for Stern is a stratification of progressively more complex functions extending over the first two years of life.

A crucial point for our discussion here is the neural development of the brain in newborns; at birth the brain is not completely developed, and it undergoes profound transformations during the first year of life. It is far from clear whether the brain of a newborn is already endowed with the necessary functional properties that would make it possible to refer to genuine consciousness.? Lacking the possibility of obtaining verbal reports of the state of 
neonate consciousness, it becomes extremely important to understand whether the brain is in a condition to permit conscious experience. If this is not the case, we cannot speak of consciousness in newborns, and alternative explanations must be found to account for their behaviour, starting with their precocious and amazing imitative capacities. Recent research on mirror neurons (Rizzolatti et al. 1996) could, for example, explain the capacity of newborns to imitate facial expressions, without the need to postulate consciousness. Imitation would simply be a semiautomatic neural response to a given stimulus, due to the existence of some highly specialized neurons - the so-called mirror neurons. These neurons continue to be operative in adult brains too, with only one relevant difference: adults, due to cultural and environmental conditioning, have inhibited their immediate imitative response, while newborns' behaviour is still characterised by automatic imitation.

However, a description couched purely in terms of mirror neurons does not explain the variety and richness of neonate infant behaviour and their nondeterministic responses to one and the same stimulus, as Tronick's experiment has shown. The richness and variety of their responses makes it difficult to think in terms of purely stimulus-response patterns, and certainly meets one of the conditions indicated by Eco for semiosis, i.e. a certain degree of freedom in response to a stimulus and a non-total predictability of behaviour.

We are facing here an apparent paradox, because on the one hand we can see that neonates are clearly engaged in semiotic behaviours, able to master interactive situations with a high degree of competence, on the other hand there are good reasons to doubt their being endowed with full consciousness, since their brains do not have yet the functional properties necessary for this. Certainly, when at age three months they react to the "still face" experiment in the complex ways that Tronick has demonstrated, they do not have representations in the classical sense of the term: mental representations that internally reproduce external states of affairs. In semiotic terms we could say that they still do not possess a type on the basis of which they can confront what they see. How can they then manage to recognize anything?

One possible way out of such a paradox is to abandon the classical view of representations, and start investigating different, alternative ideas of representation and mind. 


\section{The semiotic field}

Discussing earlier the notion of $\mathrm{C}$-space as described by Eco, I used the word "internalism" to denote an exclusive focus on processes occurring within each single organism. In such a framework semiosis coincides with the appearance of a space for mediation and distance - which is precisely what $\mathrm{C}$-space is within the specific organism we are considering, a space that is very similar to consciousness itself.

My suggestion is to now move from an internalist perspective to what could be defined as an extermalist perspective. Instead of investigating the inner world of the organism where semiotic processes are supposed to occur, let us turn to the external field where interaction between the individual, the environment and other involved subjects takes place. The methodological advantages of such a move are quite evident: we do not have to worry any longer about the existence of an inner - conscious - state that would be responsible for the semiotic capacity, and whose empirical existence, at that stage, could only be a matter for speculation. Instead, we shall attempt to describe the field in which semiotic events occur and display their sense-making potential; I call this field the semiotic field.

It is the semiotic field in itself that now becomes the object of semiotic inquiry, a portion of the actual world that we are able to isolate and describe with semiotic tools and methodologies. Semiosis starts there, in the complex interactions between body, environment and other organisms; consciousness, if we still want to maintain this notion, is, so to speak, a consciousness that extends to and characterises the semiotic field as a whole, rather than merely being an internal state of a single organism.

This is not, of course, an absolutely new idea: the Russian psychologist Vygotsky in the thirties made claims of primacy of an external, interpsychological level of functioning over the internal, intra-psychological mental world of the child. According to Vygotsky a significant number of normal human psychological processes could be understood as internalised versions of processes that are inherently social in nature. ${ }^{8}$

Today, recent empirical data from I.R., especially the microanalyses of videos of neonates and infants in interaction with their immediate environments that modern technology makes possible, allow us to further develop these seminal intuitions, and to reach a better understanding of their conse- 
quences for our present problem, i.e. the - relative - autonomy of semiosis in relation to individual forms of consciousness.

From our point of view, the crucial question then becomes the following: how can semiosis first develop in this larger semiotic field? To better understand this point let us consider the imitative phenomena depicted by Meltzoff and his colleagues in their experiments which are so relevant in discussing early semiotic competence in newborns. We can easily accept an initial description in terms of a reflex action sequence, based on the existence of specialized forms of neural activity, such as in the case of mirror neurons. In this perspective, the imitative behaviour of newborn infants does not require any semiotic consciousness, and may well be the effect of an automatic neural response to some given stimulus. The neonate infant does not have to "understand" the facial gesture or have any internal representation of it; her behaviour might well be an instinctive answer to an environmental stimulus that probably developed on an evolutionary basis. We can easily imagine that most of the behaviour of newborn children depends on the need to guarantee themselves necessary attention and care on the part of adult caregivers, and imitative behaviour may well be a device functioning in that direction.

What is at stake in an externalistic perspective is not so much what happens in the mind (or the brain) of the neonate infant, but rather how the semiotic field facilitates the emergence of semiosis and sense on the basis of her behaviour. How, in other words, a - possibly - automatic response is able to become part of a highly complex semiosic activity. In order to understand this, we have to shift attention from the mental apparatus of the infant to the semiotic field as an integrated whole, and take into account not only the single organism (the neonate infant in our case) but also the complex interactive system of the infant and the mother, their reciprocal influences and the system of activities, both behavioural and mental, that emerge out of the interaction of their respective behaviours in the field. "

All neonate behaviour, gestures, movements and expressions - independently of their being conscious behariours or merely reflex actions - are "received" by the mother, interpreted in some way and "responded" to. In this constant "making sense" of what the infant does, which is a basic component of taking care of an infant, there is certainly a projection of intentional schema

9 I refer here to the mother child dyad, however the picture may well be more complex, and should also take into account the presence of other persons. 
that might very well belong more to the adult's world than that of the infant. As Stern noticed, it is impossible to have interactions with very young children without attributing to them human qualities, intentions, motivations. Adults treat children as if they were already what they will later become. The point is that it is precisely such a projection of adult expectations that contributes to their becoming intentional conscious beings, and this projection process is therefore a relevant part of the semiotization process.

Think of all the rich verbal descriptions that mothers perform while dealing with their newborn infants much before these infants can understand them. Much of this talk represents a continuous activity of framing (Goffman 1974) of what is going on, which is at the same time a description, an interpretation and also offers emotional and pathemic support for what the infant is doing. But it is certainly in the corporeal modality of non-verbal communication that the mother interacts most with the infant. Stern has described in very precise ways the complex phenomenon of synchronization that regulates the interactive "dance" of mother and child, which he calls attunement.

In this way some behaviours are reinforced and tend to get repeated over time, others are discouraged and over a certain period of time tend to become less frequent. The first imitative smile of a newborn child might very well be a reflex action due to a given mirror neuron, but when it receives a warm answer by the mother who in her turn smiles back at her infant producing a reinforcing effect, a complex semiotic cycle starts to take place. The infant will tend to repeat the same behaviour that turned out to be so "successful" for him or her in terms of environmental response in that it received such a positive and emotionally adequate response. Successful behaviour will tend to be repeated over and over and became a regular form of (inter)action.

Now, the sequence I just described is precisely what Peirce called the creation of a habit. According to Peirce, the habit is a tendency to an action that stabilizes the semiotic process; it is a form of emergent regularity on which the whole semiosic process is centered.

Multiply reiterated behaviour of the same kind, under similar combinations of percepts and fancies, produces a tendency - the babit - actually to behave in a similar way under similar circumstances in the future (C.P. $1.560-62)$. 
The field of reciprocal mother-infant interaction that Stern and Infant Research have so effectively described is at the same time the intersubjective space where the Self of the child is given a possibility of constituting itself, and it is also where semiosis first takes place: these two processes are indeed two aspects of one and the same process.

In this vein, we can think of the mother's affective responsive to the neonate infant's behaviour as an interpretant of that behaviour, i.e. a more developed sign that is created on the basis of the effect on the organism of the mother of the first sign. In the first place we have an emotional interpretant, but emotions in their turn are embodied in gestures, movements, expressions ${ }^{10}$ that represent a correspondent variety of pragmatic interpretants. Emotions, feelings and thoughts of the mother, together with her corporeal interactions with her infant child - Stem's interactive dance - can be seen as a complex system of emotional and pragmatic interpretants that contribute to the creation of habits on the part of the infant, stabilizing his or her behaviour and interactions with the environment in a dynamic cycle where interpretants and habits of both mother and child reciprocally interact with and influence each other.

This is the semiotic field of interaction, and it is precisely within this field that semiosis first emerges. The emotional, mental, bodily, gestural and linguistic responses of the mother to the child are all ways of giving sense to and making meaningful actions that otherwise might well be seen as no more than simple reflex actions. But if each single action might well be seen as a reflex, what is going on in the whole field at any given time cannot. It is important to emphasize that meaning is not in what the child does in itself, nor exclusively in the interpretative activity of the mother; meaning and sense are created in the relational field between the two; indeed, they are this field, and this field is precisely what I refer to as the semiotic field, or field of semiosis. In a more general way we could say that semiosis is neither in the object alone, nor in the subject alone, but in the interactive coupling of the two, semiosis is the end result of coordinated forms of action - of doing things together.

Using Eco's notion of C-space, we could say that it is within the semiotic field, and not so much in the infant's mind that we can find the crucial space that is the basic, qualifying condition for the very existence of semiosis. The semiotic field is not a deterministic environment, but rather a domain that 
permits a large number of degrees of freedom, since quite different habits may develop out of the same initial reflex actions, depending on the ways in which the mother-infant interaction process develops over time. The different responses of the mother to what is, initially, possibly automatic forms of behaviour on the part of the neonate infant, can determine very different habits, reinforcing some specific types and courses of actions and discouraging others. This is a fact that is very well known to clinical psychologists, who pay a great deal of attention to early mother child interactions, knowing how relevant and important a mother's responses to an infant may be for its future development.

The particular perspective on the beginnings of semiosis we are sketching out here will deeply affect our way of framing the interrelated notions of consciousness, mind and representation.

\section{Distributed intersubjective semiosis: External Mind}

Most of the data coming from I.R. pose unsolvable problems for the classical representational theory of Piaget. Consider the "still face" experiment of Tronick: at two and three months infants already have quite complex expectations regarding their mother's behaviour, since they immediately recognize a change in her usual patterns of behaviour and react to these in highly differentiated ways. In order for them to be able to do that it is necessary to postulate that they have some memory of the relationship, and of the usual sequence of interactions within it. Now, according to Piaget, full representational capacity develops much later, at approximately 18 months. We are facing here the paradox of infants displaying a complex range of semiotic activity linking memory, expectations, adequate responsive behaviour without their having a developed system of internal representations to support this activity. The way out of this paradox consists, I believe, in a quite different way of looking both at what representations are, and at the relationship between the "inner" representational world of the infant and the so called "external" world.

In the classical view, representations are internal schemas that represent an external reality; they develop gradually through interactions with the environment by way of experience and learning. But Tronick's experiment suggests an alternative view: the relational memory that very young children already have, might not be a representation in the classical sense, but rather a capacity to foresee and anticipate other people's behaviour and adapt its own functional responses to this behaviour. 
If this is the case, rather than in terms of mental schemas we should be thinking in terms of ongoing processes in shared inter-subjective space where both semiosis and mind come to acquire a different sense. Semiosis is not - or not only - a basic feature of a conscious organism, but a distributed property of a wider social field, since it crucially depends on the combined interactions of many different agents. In the same vein mind is not anymore an exclusively internal device, but, so to say, an external distributed mind."1

The external mind is what regulates the semiotic field, an intersubjective space that is constructed by both of the interacting actors, the mother and child, together with their wider physical and socio-cultural environment. The external mind becomes, so to speak, the sedimented joint memory of ongoing experiences of intersubjective interaction and semiosis, rather than merely being an internal propriety of each individual mind: a distributed property of the wider semiotic field, in a way very similar to what we nowadays see referred to as "distributed cognition".

It is in the external world of interaction with others that semiosis actually begins, and it is only subsequently that the individual mind of the child is able to develop a properly autonomous semiotic system. A perspective of this kind is surprisingly close to the position of the psychoanalyst Wilfred Bion (1962, 1965, 1967, 1970). For Bion, intersubjective relation is of fundamental relevance in determining the very possibility of autonomous thought and a thinking apparatus; in other words, it is the basis for the possibility of any kind of semiotic functioning. Bion (1962) theorizes the existence of a proto-mental apparatus that does not represent experiences, but can only present them, starting from perceptual data, somatic excitements and sense impressions that Bion called beta elements. Beta elements cannot be used in order to think, they are not yet mental content and, as such, cannot be "digested" by the mental system, but can only be expelled from it. As they are, they are not representations, nor can they become the object of representations, but at the same time these beta elements - i.e. feelings, affects and perceptual data - are the basic elements on which basis all thought subsequently will become constituted.

11 It is interesting to notice that a similar idea can be found also in Peirce (sce for example C.P. 7.364 and 7.557 ). If in his writing the notion of external mind often seems to take on a metaphysical shadow, the analysis of concrete situations, such as early interactions between mother and child we have been discussing here, can help us to confront and better understand such complex philosophical issues with the help of detailed empirical descriptions of actual behaviours through which habits emerge. 
The unstructured experience of beta elements becomes something usable for thinking only when it is transformed by a specific function that Bion calls the alpha function, that converts beta elements into alpha elements, which can become thoughts. The alpha function however is not a function internal to the organism, in that it does not belong to the infant nor to his mental apparatus, but comes from the mother: mind can develop only through a relationship with another human being. It is the mother who transforms the unthinkable, terrifying experiences of the infant into possible thoughts, into semiotized content, we could say. In order to do so the mother has to be able to receive and contain the infant's beta elements, and give them back processed as alpha elements, which is to say as thinkable content. In semiotic terms, such a process could be described as the way semiotic form is given to unformed matter: a process of semiotization, where the mother acts as the operator of a transformational device. According to Bion she can do so through her own mental apparatus, in the moment she is able to think her infant. ${ }^{12}$ Bion uses the French word reverie to refer to this particular form of maternal thinking: a kind of shared dreaming linking the mother's and infant's experiential worlds.

Independently of the different theoretical framework and psychoanalytic meta-language used by Bion, there are clear similarities between his approach and the way in which I have suggested we look at the first formations of semiosis, while at the same time making reference also to Peirce's semiotics. In both cases, thought, semiosis and meaning can emerge only from the intersubjective relationship with its capacity to shape and transform infant experience. Both approaches are, in this sense, externalist, since they presuppose an environment, a field of successfully functioning interactional relationships as necessary pre-conditions for the development of an internal world.

From this point of view, Bion's position is very interesting: according to him, the child first develops thoughts and only later, a mental apparatus that enables it to think. This paradoxical inversion of the usual progression - first the apparatus and then thought - is quite revolutionary, since it emphasizes the intersubjective, interactive nature of mind, as something that extends far beyond the subject, in a very similar vein to our previously postulated notion of external mind. Our mental apparatus is the result of our thoughts, and not their cause, and thoughts in their turn are generated within the field of intersubjec-

12 Remember that for Bion thinking is not a purely cognitive function, but includes emotion and feeling. 
tive relationship, and are not the simplistic effect of some ontogenetic need. In a provocative way we might say that relation is the real Organon for thinking.

At this point we are in a position to have a closer look at the instant when semiosis actually starts taking place within the single organism, in the child's consciousness itself.

\section{From habits to consciousness}

The picture I have tried to sketch out so far suggests a priority of relation over individual mind: semiosis begins in the semiotic field, within an intersubjective relational field, and can only afterwards become interiorised by the infant in a conscious way. The semiotic field precedes the internal mind, but it would be a mistake to see external world and individual mind as two separate domains; there is no clear cut separation between the semiosis of the environment and the consciousness of the individual. What at the beginning can be seen as mere reflex actions, mechanical laws of matter, in a sense, then becomes, by way of the constitution of habits and the acquisition of meaning in the semiotic field of interpersonal relationship, a living, psychological reality.

The path that goes from reflex actions to habits and conscious behaviour will certainly require much closer and much more detailed description that far exceeds the intentions of the present work. It will be sufficient to emphasize here that in order for semiosis to manifest itself as conscious processes, i.e. for infants to be seen as having developed a fully functional semiotic consciousness, corporeal experience in the semiotic relational field of interpersonal interactions must play a major role.

This was well known to Freud, who claimed that the first Ego is a corporeal Ego (Freud 1923). We could think of such a corporeal Ego as a feeling body, a body made of sensations, feelings and emotions; remembering, too, that for Freud, as well as for William James, student, colleague and life-long friend of Peirce, emotions are essentially, and in the first place, the modality by way of which we best perceive our own bodies.

Even before having developed a fully functional semiotic consciousness, our body is not mere pre-semiotic matter, but a highly complex semiotic system, endowed with feelings, emotions and the capacity to make subtle distinctions and respond in competent and meaningful ways to salient environmental stimuli. The body, and the emotions connected with our own subjective perceptions of it, constitute the very basis for semiosis in that they are already' 
semiosic processes; the origins of both semiosis and consciousness, in infants, are rooted here.

How the body becomes the vehicle for the development of a full semiotic consciousness will be the object of a subsequent chapter of my research. For the time being I would like to conclude by quoting a passage from Peirce, who towards the end of the $19^{\text {th }}$ century commented as follows on an observable empirical phenomenon that today is a well recognized, well documented fact in Infant Research:

A very young child may always be observed to watch its own body with great attention. There is every reason why this should be, for from the child's point of view this body is the most important thing in the universe. Only what it touches has any actual and present feeling, only what it faces any actual colour; only what is on its tongue has any actual taste (C.P. 5.213-63).

\section{References}

Benzoni, S. (2004). Il presente discontinuo. Esperienza, coscienza e soggettività nel neonate. Milano: Il Saggiatore.

Bick, E. (1964). Notes on Infant Observation in Psychoanalytic training. Intermational Joumal of Psychoanalysis 45, 558-566.

Bion, W. (1962). Leaming form Experience. London: William Heinemann.

Bion, W. (1965). Transformations: Change from Leaming to Growth. London: William Heinemann Medical Books.

Bion, W. (1967). Second Thougbts: selected papers on psycho-analysis. London: William Heinemann Medical Books.

Bion, W. (1970). Attention and Interpretation. London: Tavistock Publications.

Dennett, D. (1991). Consciousness Explained. London: Little Brown \& Co.

Eco, U. (1979). A theory of Semiotics. Bloomington, Indiana: Indiana University Press.

Eco, U. (1988). On Semiotics and Immunology. In E. Sercarz, F. Celada, N. A. Mitchison, \& T. Tada (Eds.), The Semiotics of Cellular Communication in the Immune System, NATO ASI Series, vol. 23. Berlin, New York: Springer Verlag.

Edelman, G. M. (1989). The Remembered Present. A Biological Theory of Consciousness. New York: Basic Books.

Edelman, G. M. (2004). Wider than the Sky. The Pbenomenological Gift of Consciousness. New Haven: Yale University Press.

Freud, S. (1914). On Narcissism: an introduction, S.E. 14: 67-102.

Freud, S. (1923). Ego and Id, S.E. 19: 17-25.

Goffman, E. (1974). Frame Analysis. An Essay on the Organisation of Experience. Cambridge, MA: Harvard University Press.

Hjelmslev, L. (1943). Prolegomena to a Theon' of Language (English tr.). Madison: University of Wisconsin, 1961. 
Mahler, M. \& Furer M. (1968). On Human symbiosis and the vicissitudes of inditiduation. New York: International Universities Press.

Mahler, M., Pine, F., \& Bergman, A. (1975). The Psychological Birth of the Human Infant. New York: Basic Books.

Meltzoff, A. N. (1989). Foundations for Developing a Concept of Self: The Role of Initation in Relating Self to Other and the Value of Social Mirroring, Social Modeling, and Self Practice in Infancy. In D. Cicchetti \& M. Beeghly (Eds.), The Self in Transitions: Infangy to Childhood. Chicago: University of Chicago Press.

Meltzoff, A. N. and Moore, M. K. (1977). Imitation of facial and manual gestures by human neonates. Science 198, 75-78.

Morris, C. (1938). Foundations of the Theory of Signs. International Encyclopaedia of Unified Science 1-2: University of Chicago Press.

Nagel T. (1979). Mortal Questions. New York: Cambridge University Press.

Neisser, U. (Ed.) (1993). The Perceived Self. New York: Cambridge University Press.

Peirce, C.S. (1934-48). Collected Papers. Cambridge, MA: Harvard University Press.

Pozzato, M.P. \& Violi, P. (2002). La messa in discorso delle passioni. Il caso di Segreti e bugie di Mike Leigh. VS 93, 127-154.

Rizzolatti, G., Fadiga, L., Gallese, V., Fogassi, L. (1996). Premotor Cortex and the Recognition of Motor Actions. Cognitive Brain Research, 3, 131-141.

Saussure, F. de (1916). Cours de linguistique générale, Paris : Payot.

Searle, J. R. (1997). The Mystery of Consciousness. New York: New York Review Books.

Stern, D. (1985). The Interpersonal world of the Infant: $A$ View from Psychoanalysis and Developmental Psychology. New York: Basic Books.

Trevarthen, C. (1989). Signs before Speech. In T. A. Sebeok \& J. Umiker-Sebeok (Eds.), The Semiotic Web. Amsterdam: Mouton De Gruyter.

Trevarthen, C. (1993). The Self Born in Intersubjectivity: the Psychology of Infant Communicating. In Neisser (Ed.), The Perceived Self. New York: Cambridge University Press.

Tronick E. Z., Als, H., Adamson, L., Wise, S., \& Brazelton, T. B. (1978). The Infant's Response to Entrapment between Contradictory Messages in Face-to-Face interaction. Joumal of American Academy of Child Psychiatry 17, 1-13.

Tronick, E. Z. (Ed.) (1982). Social Interchange in Infancy: Affect, Cognition and Communication. Baltimore: University Park Press.

Vygotsky, L.S. (1978). Mind in Society. Cambridge, MA: Harvard University Press.

Vygotsky, L.S. (1997). The History of the Development of Higher Mental Functions In The Collected Works of L.S. Vygotsky, Volume 4. New York: Plenum Press. 